\title{
Potential Pithfalls in Using HPLC and its Interpretation in Diagnosing HbS
}

\section{Dr. Sona B. Nair*}

Department of Assisted Reproduction and Genetics, Jaslok Hospital and Research Centre, Mumbai, India

\section{Article Info}

\section{Article Notes}

Received: July 19, 2018

Accepted: September 4, 2018

*Correspondence:

Dr. Sona B. Nair, Department of Assisted Reproduction and

Genetics, Jaslok Hospital and Research Centre, Mumbai, India; Email: sonabnair@rediffmail.com

(C) 2018 Nair SB. This article is distributed under the terms of the Creative Commons Attribution 4.0 International License.

\section{Introduction}

Hemoglobinopathies are the most common group of autosomal recessive monogenic disorders worldwide. They include both thalassemias and structural hemoglobin variants. More than 1,100 hemoglobin variants have been detected so far out which majority of them are new variants while some others are very commonly found in some populations ${ }^{1,2,3}$. Sickle hemoglobin ( $\mathrm{Hb} \mathrm{S}$ ) is a very common structural variant found worldwide. Sickle cell disorder is a group of hereditary blood disorders caused due to a mutation in the $\beta$ globin gene resulting in the production of abnormal hemoglobin called sickle hemoglobin ( $\mathrm{Hb} \mathrm{S}$ ). $\mathrm{Hb} \mathrm{S}$ is so called because the abnormal hemoglobin causes the red blood cells to become rigid and sickle shaped which blocks blood flow and breaks down easily ${ }^{4}$. Severity in sickle cell disorders varies and the symptoms range from anemia to vaso-occlusive crises which over a period of time affect multiple organs with chronic deterioration over the time ${ }^{5}$. When the sickle mutation is inherited with any other globin gene mutation it is called variant sickle cell syndromes and the clinical severity may differ when compared to homozygous sickle mutation ${ }^{6}$. Early detection of sickle cell disease (SCD) helps in the prophylactic therapy ${ }^{7}$ and proper management of the disease ${ }^{5}$. This is the reason why new born or neonatal screening programs for sickle cell disorders have been initiated in many countries where the prevalence of sickle cell anemia is very high $^{8,9}$.Therefore it becomes all the more important that extreme precaution has to be taken while diagnosing sickle cell disease as it provides a direction for life long treatment and prophylaxis of the patient along with counselling of the parents for prenatal diagnosis or pre implantation genetic diagnosis in future pregnancies ${ }^{3,10}$. Bone marrow transplant with HLA identical donors and use of hydroxyurea may be beneficial to reduce frequency of crises and reduce tissue damage ${ }^{11}$.

\section{Techniques for Differentiating Between Hbs and its Variants}

There are a number of different methods which can be used for the detection of $\mathrm{HbS}$ and its variants. But each of these tests has its own limitations and therefore they have to be used carefully and in combination to get a proper diagnosis. The techniques include observation of peripheral smear under microscope, solubility tests $^{11,12}$, sickling test ${ }^{11}$ and alkaline electrophoresis or cellulose acetate electrophoresis ${ }^{12}$ which gives a fairly accurate diagnosis of $\mathrm{Hb} \mathrm{S}$ but the final confirmation of the diagnosis has to be done by DNA analysis.

Sickling test or sickle cell test is a simple blood test which detects if a red blood cell changes its shape into a crescent (sickle) shape 
on mixing of a chemical ( $2 \%$ sodium metabisulphite) with blood that depletes the oxygen from the RBC's.

Sickle cell solubility test is another simple method based on the relative insolubility of the sickle hemoglobin in reduced state in high molar phosphate buffer solution. The presence of sickle hemoglobin (HbS) forms a precipitate producing a turbid solution thus preventing the light from passing through the solution when compared with the normal hemoglobin which dissolves completetly $^{13}$. In case of $\mathrm{Hb} \mathrm{S}$ solubility test there are chances of picking up false positives in presence of other hemoglobin variants or false negatives in presence of low hemoglobin or hematocrit (HCT) values and the test cannot differentiate between a carrier and disease state for sickle cell disease. But the sickling test along with solubility test and peripheral smear can still be used as a reliable screening method prior to hemoglobin electrophoresis ${ }^{12}$. Cellulose acetate electrophoresis involves the preparation of hemolysates from red blood cells which is then applied to cellulose acetate strips. These strips are then placed in electrophoresis tanks containing buffer chambers and the electrophoresis is carried out at a constant voltage. The different hemoglobin fractions get separated out on the cellulose acetate strips depending on their mobility ${ }^{14}$. The $\mathrm{Hb} \mathrm{S}$ bands can be detected easily but due to the presence of other hemoglobin variants with same mobility as $\mathrm{HbS}$ it may become difficult to interpret the results. This may lead to misdiagnosis if another method is not used to confirm the diagnosis.

However with the advent of new automated technology like high performance liquid chromatography (HPLC) which is user friendly and at the same time gives quick results almost all the old techniques have been discontinued in most of the laboratories on the pretext of the techniques being cumbersome and outdated.

\section{Detection of Variants Using HPLC}

HPLC is the method of choice in many laboratories and remains the most efficient tool in detection of thalassemias and the abnormal hemoglobin by fast and simultaneous qualitative and quantitative estimations of hemoglobin fractions. It is highly reproducible, offers simplicity with automation, superior resolution and rapid result ${ }^{15}$. The use of this technology has increased 12 fold in last few years ${ }^{16}$. The basic technology of HPLC is based on the time required for gradient elution of the different hemoglobin fractions. This is called the retention time (RT). Each hemoglobin has a particular retention time which falls in the time range set by the manufacturer for the particular hemoglobin fraction. The retention time is measured form the time of sample injection to maximum point of each peak $^{17}$. The hemoglobin retention time is calculated and plotted on a chromatogram ${ }^{18}$. Identification of known and unknown peaks of hemoglobin is made by comparing with known $\mathrm{Hb}$ retention times ${ }^{19}$. There are over 1000 variants described. Many of the known and unknown variants may share a common $\mathrm{RT}^{19}$. Since the specificity of the detection windows have a wide range, all the variants migrating in the same range will be eluted out in the same window. Thus all the variants with a retention time similar to $\mathrm{HbS}$ for example will be eluted out in $\mathrm{Hb} \mathrm{S}$ window. This is very risky as it can lead to misdiagnosis in case of new variants mimicking $\mathrm{Hb} \mathrm{S}$ and eluting out in the $\mathrm{HbS}$ window. Thus a confirmatory test should be done along with HPLC prior to giving a final diagnosis ${ }^{17,19,20}$. DNA analysis is not possible in all laboratories since it requires a lot of expertise in performing the test and interpretation. Therefore simple tests as mentioned above like peripheral smear, sickling test and alkaline electrophoresis will help to distinguish between sickle and sickle like variants. This is extremely important from management point of view of the patients. If the patients are labelled as sickle cell based solely on HPLC report and if they are started on drugs such as hydroxyurea or are given transfusions if and when required it may cause severe complications in patients if they are actually some other variant and not $\mathrm{Hb} \mathrm{S}^{21}$. Hydroxyurea is a cytotoxic drug given to sickle cell patients for increasing the fetal hemoglobin level and to reduce the painful crises which if given to patients who are not $\mathrm{HbS}$ may prove detrimental to their health ${ }^{22}$.

There has also been report of discrepancy between two different kits used for testing of Hb S by HPLC ${ }^{23}$.Though HPLC is a powerful tool in the evaluation of hemoglobin variants depending on the peak shape, position and retention time it has its own limitations and cannot be used as a stand-alone method for identification of hemoglobin variants diagnosis based solely on retention times. The results should be cross checked with another technique but the final diagnosis or confirmation should always be done by DNA analysis in laboratories which have such facilities or by sending the samples for DNA analysis to laboratories which have molecular analysis facility if there is no facility for the molecular analysis in the same laboratory.

\section{HbS and Variants Mimicking HbS on HPLC and Alkaline Electrophoresis}

HPLC is considered as a reliable tool for detecting different hemoglobin variants based on their retention times. About thirty different variants have been reported to be eluting out in the $\mathrm{Hb} \mathrm{S}$ window with the retention time between 4.31 and $4.63^{18}$. Two new hemoglobin variants (Hb Vellore and $\mathrm{Hb}$ Haagladen) have been recently reported to elute in the $\mathrm{HbS}$ window on HPLC and would have been misdiagnosed if no other tests were done to confirm the variants $^{24,25}$. Hb Handsworth is another variant reported in the alpha globin gene which shows a prominent peak eluting in the $\mathrm{Hb} \mathrm{S}$ window on HPLC along with a very small secondary peak $^{26}$. In this case since the major prominent 
peak was $\mathrm{Hb} \mathrm{S}$, the small secondary peak would have been overlooked as an artefact or reported as unknown thus giving the impression of $\mathrm{HbS}$ in the absence of other confirmatory tests or molecular analysis. In this case the gel electrophoresis showed a band in the $\mathrm{HbS}$ region along with a very faint band corresponding to the secondary small peak. The sickling test however was negative ${ }^{26}$. This case further emphasizes the fact that it is important to have a combination of techniques along with HPLC to avoid any misdiagnosis though the final confirmation has to be done by molecular analysis. In this case sickling test played a very important role in differentiating between $\mathrm{Hb} \mathrm{S}$ and $\mathrm{Hb}$ Handsworth and it provided a clue for the presence of a variant other than $\mathrm{HbS}$ for molecular analysis ${ }^{26}$.

Precautions should also be taken while interpreting the results using cellulose acetate electrophoresis. A number of variants have been reported with mobility similar to that of $\mathrm{HbS}$. Table 1 shows some of the variants reported with same mobility as $\mathrm{Hb} \mathrm{S}$ on cellulose acetate electrophoresis (http://globin.cse.psu.edu). Hb Lepore (caused due to $\delta \beta$ fusion) also has the same mobility as $\mathrm{Hb} \mathrm{S}$ on cellulose acetate electrophoresis. These variants can be distinguished from each other when they are run on HPLC or capillary electrophoresis (CE) and the final confirmation done by DNA analysis.

In addition to the HPLC technique, capillary electrophoresis (CE) along with HPLC is a very powerful method allowing a better automated separation and estimation of different abnormal hemoglobin fractions that may otherwise be undetected or misdiagnosed on HPLC $^{27,28}$. CE separates hemoglobin variants based on electroosmotic flow and electrophoretic mobility in alkaline buffer. Mass spectrometry is another important technique for identification of different hemoglobin variants. Mass spectrophotometry when used in combination with HPLC techniques will help in detecting many variants which may cannot be clearly classified based on HPLC alone ${ }^{29,30}$.

Thus whatever be the protocol followed in different laboratories for detecting hemoglobinopathies and hemoglobin variants, it always has to be a combination of two or three different techniques ${ }^{31}$ to avoid any misdiagnosis which may prove fatal to the management

Table 1

\begin{tabular}{|c|c|}
\hline$\alpha$-chain variants & $\beta$-chain variants \\
\hline Hb G-Philadelphia & Hb D-Punjab \\
\hline Hb Hasharon & Hb G-Galveston \\
\hline Hb Stanleyville II & Hb G-San Jose \\
\hline Hb Memphis & Hb P-Galveston \\
\hline Hb Russ & Hb Osu Christiansborg \\
\hline Hb G-Pest & Hb Summer Hill \\
\hline Hb G-Waimanalo & Hb Machida \\
\hline & Hb Makassar \\
\hline
\end{tabular}

and therapy of the patient and also for genetic counselling of the family.

\section{References}

1. Steinberg MH,Benz EJ. Hemoglobin synthesis, structure and function. Hoffman R eds. Hematology, basic principles and practice Churchill Livingstone New York. 1991; 291-302.

2. Hardison RC, Chui DHK, Giardine B, et al. Hb Var: a relational database of human hemoglobin variants and thalassemia mutations at the globin gene server. Hum Mutat. 2002; 19: 225-33. (http://globin.cse. psu.edu).

3. Giordano PC. Strategies for basic laboratory diagnostics of the hemoglobinopathies in multi-ethnic societies: interpretation of results and pithfalls. Int J Lab Hemat. 2013; 35(5): 465-479.

4. Naik RP, Haywood C Jr. Sickle cell trait diagnosis: clinical and social implications. Hematology Am Soc Hematol Educ Program. 2015; 160 167.

5. Ashley-Koch A, Yang Q, Olney RS. Sickle hemoglobin ( $\mathrm{HbS}$ ) allele and Sickle Cell Disease: A HuGE Review. American Journal of Epidemiology. 2000 ; $151(9): 839-845$.

6. Smith EW, Conley CL. Clinical features of the genetic variants of sickle cell disease. Bull John Hopkins hospital. 1954; 94: 289.

7. Davies EG, Eddington C, Lottenberg R, et al. Penumococcal vaccines for sickle cell disease. Cochran Database System Rev. 2004(1): CD003885.

8. Watson MS, Mann MY, Lloyd-Puryear MA, et al. Newborn screening: Toward a uniform screening panel and systemic executive summary. Pediatrics. 2006; 117(5): S296-S307.

9. Upadhye DS, Jain DL, Trivedi YL, et al. Neonatal screening and clinical outcome in children with sickle cell disease in Central India. PloS One. 2016; 11(1): e0147081.

10. Oteng-Ntim E, Meeks D, Seed PT, et al. Adverse maternal and prenatal outcomes in pregnant women with sickle cell disease:systematic review and meta-analysis.Blood.2015; 125: 3316-3325.

11. Lapourmeroulie $\mathrm{C}$, Benkerrou $\mathrm{M}$, Odievere $\mathrm{MH}$, et al. Decreased plasma endothelium-1 levels in children with sickle cell disease treated with hydroxyurea. Haematologica. 2005; 90: 401-403.

12. Okwi AL, Byarugaba W, Parkes A, et al. The reliability of sickling and solubility tests and peripheral blood film method for sickle cell disease at screening at district health centers in Uganda. : Clinics in Mother and Child Health. 2010; 7(1): 1205 -1210.

13. Raper AB. Solubility test for Hb S. Br Med J. 1971; 1(5746)460.

14. Kim HC, Atwater J, Schwartz E. Separation of hemoglobins. Williams WJ, Beutler E, erslev AJ, Litchman MA, eds. Hematology. 1990; 16111619, McGraw-Hill New York.

15. Hoyer JD, Scheidt RM. Identification of hemoglobin variants by HPLC. Clin Chem. 2005; 51(7): 1303-1304.

16. Hemoglobin and Clinical Microscopy Reference Committee. Hemoglobinopathies survey proficiency reports 1994-2003. College of American Pathologists, Chicago, IL.

17. Joutovsky A, Hadzi-Nesic J, Nardi MA. HPLC retention time as a diagnostic tool for hemoglobin variants and hemoglobinopathies: A study of 60,000 samples in a clinical diagnostic laboratory. Clinical Chemistry. 2004; 50(10): 10736-1747.

18. Keren DF, Hedstrom D, GulBranson R, et al. Comparison of Sebia capillarys and capillary electrophoresis with the Primus high-pressure liquid chromatography in the evaluation of hemoglobinopathies. Am J Clin Pathol. 2008; 130: 824-831.

19. Rachna Khera, Tejinder Singh, Nita Khuana, et al. HPLC in 
characterization of hemoglobin profile in thalassemia syndromes and hemoglobinopathies: A clinicohematological correlation. Indian J Hematol Blood Transfus. 2015; 31(1): 110-115.

20. Ranney HM, Jacobs AS, Nagel RL. Hemoglobin New York. Nature. 1967; 213: 876-878.

21. Serjeant GR. The emerging understanding of sickle cell disease. Br J Haematol. 2001; 112: 3-18.

22. Agrawal RK, Patel RK, Shah V, et al. Hydroxyurea in Sickle cell disease: drug review. Indian J Hematol Blood Transfus. 2014; 30(2): 91-96.

23. Upadhye DS, Jain DL, Trivedi YL, et al. New born screening for hemoglobinopathies by high performance liquid chromatography (HPLC): diagnostic utility of different approaches in resource poor settings. Clin Chem Lab Med. 2014; 52(12): 1791-1796.

24. Edison ES, Sathya M, Rajkumar SV, et al. A novel $\beta$ globin gene mutation HBB. C. $22 \mathrm{G} \rightarrow$ C produces a hemoglobin variant (Hb Vellore) mimicking Hb S in HPLC. Int Jnl Lab Hem. 2012; 34(5): 556-558.

25. Harteveld CL, Ponjee G, Bakker-Verweij M, et al. Hb Haaglanden: a new non sickling $\beta 7 \mathrm{Glu} \rightarrow$ Val variant. Consequences for basic diagnostic, screening and risk assessment when dealing with $\mathrm{Hb} \mathrm{S}$ like variants. Int Jnl Lab Hem. 2012; 34(5): 551-555.

26. Al Zadjali Al S, Al-Riyami AZ, Gravell D, et al. Potential pithfalls in the diagnosis of $\mathrm{Hb}$ Handsworth in areas with high prevalence of $\mathrm{Hb} \mathrm{S}$. Int Jnl Lab Hem. 2014; 36: 488-492.

27. Van Delft, Lenters E, Bakker-Verweij M, et al. Eavaluating five dedicated automatic devices of hemoglobinopathy diagnostics in multi ethnic populations. Int Jnl Lab Hem. 2009; 31: 484-495.

28. Nair S, Nadkarni AH, Ghosh $\mathrm{K}$, et al. Hemoglobin variants and highperformance liquid chromatography. Int Jnl Lab Hem. 2013; 35(5): e13-e14.

29. Dar R, Mitra G, Mathew B, et al. Mass spectrometry based diagnosis of hemoglobinopathies: A potential tool for the screening of genetic disorder. Biochem Genet. 2016; 54(6): 816-825.

30. Kleinert P, Schmid M, Zurbriggen K, et al. Mass spectrometry: A tool for enhanced detection of hemoglobin variants. Clin Chem. 2008; 54(1): 69-76.

31. Wajcman H, Moradkhani K. Abnormal hemoglobins: detection and characterization. Indian J Med Res. 2011; 134(4): 538-546. 